\title{
Clinical value of measurement of pulmonary radioaerosol mucociliary clearance in the work up of primary ciliary dyskinesia
}

\author{
Mathias Munkholm¹, Kim Gjerum Nielsen ${ }^{2}$ and Jann Mortensen ${ }^{1,3^{*}}$
}

\begin{abstract}
Background: We aimed to evaluate and define the general clinical applicability and impact of pulmonary radioaerosol mucociliary clearance (PRMC) on the work up of patients suspected of having primary ciliary dyskinesia (PCD). In addition, we wanted to evaluate the accuracy of the reference values used in the PRMC test.

Methods: Measurement of PRMC after inhalation of ${ }^{99 m}$ Tc-albumin colloid aerosol was carried out on 239 patients (4-75 years of age) during a 9-year period. All were referred to the nuclear medicine department because of clinical suspicion of PCD. The results were compared primarily to results from nasal ciliary function testing, to electron microscopic (EM) examination of the ultrastructure of the cilia, and to the final clinical diagnosis.

Results: Of the 239 patients, 27 ended up with a final clinical diagnosis of definitive PCD. No patients with a PRMC test that was normal or otherwise not consistent with PCD ended up with PCD as final clinical diagnosis (though a minority of patients in this group ended up unresolved in regard to PCD). Forty percent of patients with an abnormal PRMC test ended up with PCD as final clinical diagnosis. Furthermore, the PRMC test had a high rate of conclusive results $(90 \%)$. Children $<14$ years of age with normal PRMC measurements showed significantly faster lung clearance than adults with similarly normal PRMC measurements.

Conclusions: To this date, PRMC is the only test providing evaluation of the mucociliary clearance of the entire lung. Its greatest strength is its ability to reject a suspected PCD diagnosis with great certainty. In our material, this accounted for $2 / 3$ of referred patients. In addition, the test has a high rate of conclusive results. According to our analyses, reference equations on children would benefit from updated data.
\end{abstract}

Keywords: Mucociliary clearance; Diagnostic test; Primary ciliary dyskinesia

\section{Background}

Mucociliary clearance is known to be an important innate defence mechanism against inhaled microbes and irritants. Potentially harmful substances get trapped in the mucus layer lining the airways, and subsequently, the synchronised movement of the cilia propels the mucus to the pharynx where it will be swallowed. This mechanism can be hampered either by conditions affecting the constitution of the mucus (such as cystic fibrosis, chronic obstructive pulmonary disease, or asthma) or by

\footnotetext{
* Correspondence: jann.mortensen@regionh.dk

'Department of Clinical Physiology, Nuclear Medicine \& PET, Rigshospitalet,

Copenhagen University Hospital, DK-2100 Copenhagen $\varnothing$, Denmark

${ }^{3}$ Department of Medicine, Nuclear Medicine section, The Faroese National

Hospital, Torshavn, Faroe Islands

Full list of author information is available at the end of the article
}

conditions directly affecting the movement of the cilia. This last group of conditions has traditionally been divided into primary and secondary ciliary dyskinesia (PCD and SCD). PCD is a genetic disorder caused by mutations in genes in relation to the axoneme. Clinically, the patients present with cough, dyspnea, and recurrent airway infections starting from early childhood. However, it is both genetically and phenotypically a heterogeneous condition presumably reflecting the molecular complexity of the axoneme, and for this same reason, diagnosing these patients can be challenging. SCD on the other hand includes a variety of temporary, acquired defects of ciliary movement caused by viral or bacterial infection or by certain air pollutants. In some instances, it can be difficult to 
differentiate SCD from PCD because of overlapping findings in the tests meant for diagnosing PCD [1].

Although there is no definitive evidence that early diagnosis of PCD is beneficial, there is emphasis on finding and treating these patients as early as possible, since early and aggressive treatment of lung infections is thought to be crucial in the prevention of future lung damage [2-4].

The diagnosis relies on the clinical assessment of the patients combined with an array of different tests. These typically include measurement of nasal nitric oxide (nasal NO) where a low NO-value points towards PCD and vice versa, electron microscopic (EM) examination of the ultrastructure of the cilia, and microscopy of ciliary beat pattern and frequency. Genetic testing is developing rapidly, but to this date, only some of the disease-causing genes are known and currently around $65 \%$ of patients could be detected this way [5-7]. Highly specialised modalities used in only few centres are (1) culture of respiratory cells at an air-liquid interface with reanalysis of the ultrastructure of cilia and microscopy of ciliary beat pattern and frequency, (2) immunofluorescence microscopy of respiratory cells, which allows visualisation and localisation or demonstration of the absence of specific proteins in relation to the cilia, and (3) EM tomography, which due to its high resolution may be able to identify ultrastructural defects where normal EM has not determined the abnormality [7-10].

While EM of the cilia and ciliary function testing are both time consuming and somewhat invasive, nasal NO measurement is a fast, non-invasive tool that can generally be used from 5 years of age (modified techniques have been shown to be applicable from 2.5 years) $[2,11]$ when it comes to targeted case finding and excluding of PCD. But still, there is a need for further investigation when nasal NO values are either inconclusive or point towards PCD [2]. At our centre, measurement of pulmonary radioaerosol mucociliary clearance (PRMC) has been used as part of diagnostic routine tools in the work up of patients suspected of having PCD for over a decade. This method draws on the fact that patients with PCD have impaired mucociliary clearance as a result of abnormal ciliary motility [12]. This abnormal clearance pattern can be visualised for the entire lung using a gamma camera to follow the movement of an inhaled radioaerosol. PRMC is non-invasive, renders a minimal amount of radiation (less than $1 \mathrm{mSv}$ while the yearly background radiation in Denmark is 3-4 mSv), is applicable to children as young as 5 years of age (younger children will normally exhibit a lack of cooperation), and most importantly a normal PRMC can help excluding the diagnosis in patients with symptoms compatible with PCD who might exhibit SCD in the nasal biopsy $[13,14]$. In addition, the PRMC test is relatively easy to perform. A simplified protocol for the test is presented in our review published in 2013 [1]. A large number of patients referred for PRMC as work up of PCD diagnosis are children. However, our current reference equations are generated on a group of healthy people $>17$ years of age. It is still unknown if extrapolating the equations to this younger age group will bias interpretation of results.

The aim of this study is to evaluate and define the general clinical applicability and impact of PRMC on the work up of patients suspected of having PCD. Moreover, the reference values used today will be scrutinised-especially their accuracy when used in the work up of children.

\section{Methods}

\section{Study design}

The study was carried out as a register-based follow-up study. The patients were included continuously over 9 years, and their final clinical diagnosis was evaluated at the end of the study period.

\section{Patients}

In total, 239 patients were included in the study, and all were referred to the nuclear medicine department for PRMC test because of clinical suspicion of PCD. The vast majority of these had PRMC done as part of their work up for PCD in the National PCD Centre in Copenhagen at Rigshospitalet, whereas 64 patients were referred directly from departments of pulmonary medicine in other hospitals, and they were only referred to the National PCD Centre in Copenhagen if the clinical suspicion of PCD sustained after completion of the PRMC test.

Preceding the PRMC test, patients were informed that they had to be without symptoms of acute airway infections 4-6 weeks prior to the test. Some patients had their PRMC test repeated during the study period; but in this paper, when nothing else is stated, only results from the first PRMC test are used.

\section{PRMC test}

The PRMC technique has been described in detail earlier [15]. In brief, the patients inhaled an ultrasonically nebulised ${ }^{99 \mathrm{~m}} \mathrm{Tc}$-albumin colloid with a mass median aerodynamic particle diameter of $3.4 \mu \mathrm{m}$. They did 20 tidal breathings with slow inspiration followed without breath hold by forced expiration, and the radioaerosol was administered during the whole inspiration phase. Inhalation volume was not measured. Immediately after the inhalation procedure, the patients rinsed their mouth by gargling three times. Thereafter, lung radioactivity was detected by placing the patients in a supine position against a posteriorly positioned gamma 
camera, and it was ensured that a target rate of 1000 counts per second was obtained. If not, extra inspirations were made.

Measurement of lung radioactivity was performed for the next $2 \mathrm{~h}$ with static acquisitions at 0,60 , and 120 min together with two 20-min dynamic acquisitions (films) in the first hour. This was supplemented with a 15-min static acquisition after $24 \mathrm{~h}$.

Regional ventilation distribution was assessed by an ${ }^{81 \mathrm{~m}} \mathrm{Kr}$-gas scintigram. The initial ${ }^{99 \mathrm{~m}} \mathrm{Tc}$ aerosol distribution was compared to this ${ }^{81 \mathrm{~m}} \mathrm{Kr}$ ventilation distribution by calculating a penetration index (PI), which reflects how far the radioaerosol had penetrated into the lungs, thereby indicating how far the radioaerosol had to move before being cleared from the airways. Using our reference equations which are based on a cross-sectional study of 53 healthy neversmoking adults (18 to 84 years) [16], the PI, sex, and age of the subject was used to calculate his or her predicted lung retention at 1 and $2 \mathrm{~h}\left(\mathrm{pLR}_{1}\right.$ and $\left.\mathrm{pLR}_{2}\right)$. These predicted values were then compared to the actual measured lung retention at 1 and $2 \mathrm{~h}\left(\mathrm{LR}_{1}\right.$ and $\left.\mathrm{LR}_{2}\right)$ corrected for background and physical decay.

The difference between predicted and actual lung retention divided by the standard deviation was calculated as a $Z$-score for $L R_{1}$ and $L R_{2}$, respectively. The upper limit for a normal test was defined as a $Z$-score of $>1.645$ (i.e., 95 percentile), since an abnormal mucociliary clearance can only be too slow, resulting in too high retention.

The two 20-min dynamic acquisitions were used to assess mucus transport in the larger airways. When bolus transport occurred, distinctive radioactive boluses could be seen to move through the main stem bronchi and the trachea (Fig. 1). The movement was visually assessed as normal, abnormal (i.e., slow, absent, or retrograde), or inconclusive.

The interpretation of the PRMC test was based on the following three questions: (1) Were $\mathrm{LR}_{1}$ and $\mathrm{LR}_{2}$ outside the predicted values? (2) Was the bolus transport in the trachea abnormal? And (3) was focal retention seen in the airways after $24 \mathrm{~h}$ ? A "yes" to all questions indicated

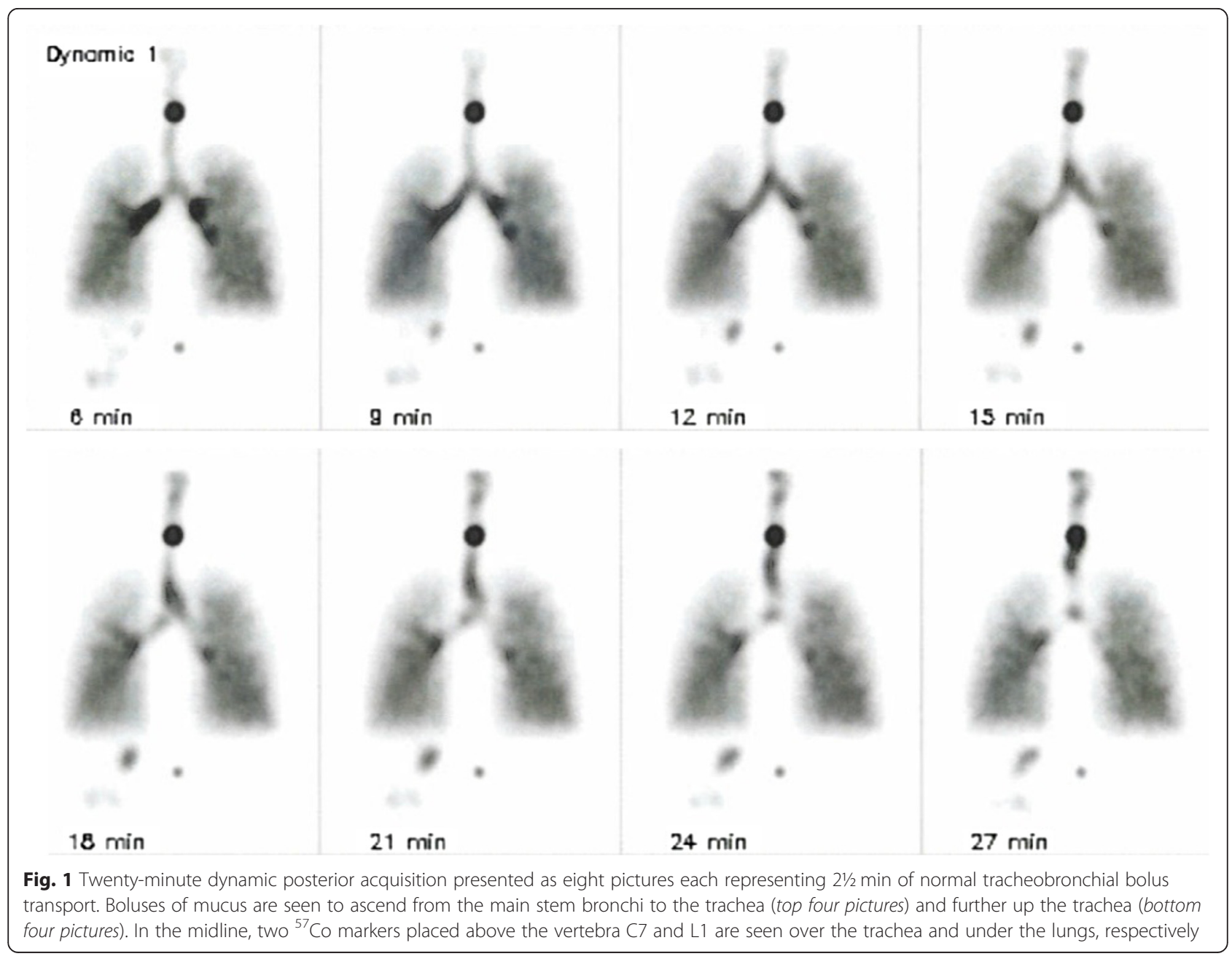


abnormal clearance, while "no" to all indicated normal clearance. A regional impaired clearance was the case, if there were one or a few focal retentions at $24 \mathrm{~h}$, while the other two parameters were normal. In other cases of inconsistencies, the test was read as inconclusive (see below).

Generally, the interpretation of the PRMC tests can be divided into three main groupings: (1) where the test is clearly abnormal rendering PCD or SCD possible explanations, (2) where the test is inconclusive whereby PCD cannot be ruled out, or (3) where the test is normal or otherwise not consistent with PCD. If for example one or a few focal retentions were seen at $24 \mathrm{~h}$, this would imply overall normal clearance with only regional impairment. Such a test would therefore be placed in group
(3). As another example, some patients show signs of SCD but not PCD (e.g., slow clearance indicated by abnormal LR1 and/or LR2 but normal retention at $24 \mathrm{~h}$ and normal bolus transport in central airways), and such a test would as well be placed in group (3). This means that PRMC has the ability to discern between PCD and SCD in some but not all cases. Examples of static acquisitions from an abnormal, a normal, and a regional abnormal test, respectively, are seen in Fig. 2.

An inconclusive test is usually a result of one of the following causes: (1) cough during examination, (2) inconsistency between $\mathrm{LR}_{1}$ and $\mathrm{LR}_{2}$ values, bolus transport, and 24-h retention, or (3) very peripheral radioaerosol deposition, which can cause the predicted normal range for lung retention $\left(\mathrm{pLR}_{1}\right.$ or $\mathrm{pLR}_{2}+1.645$

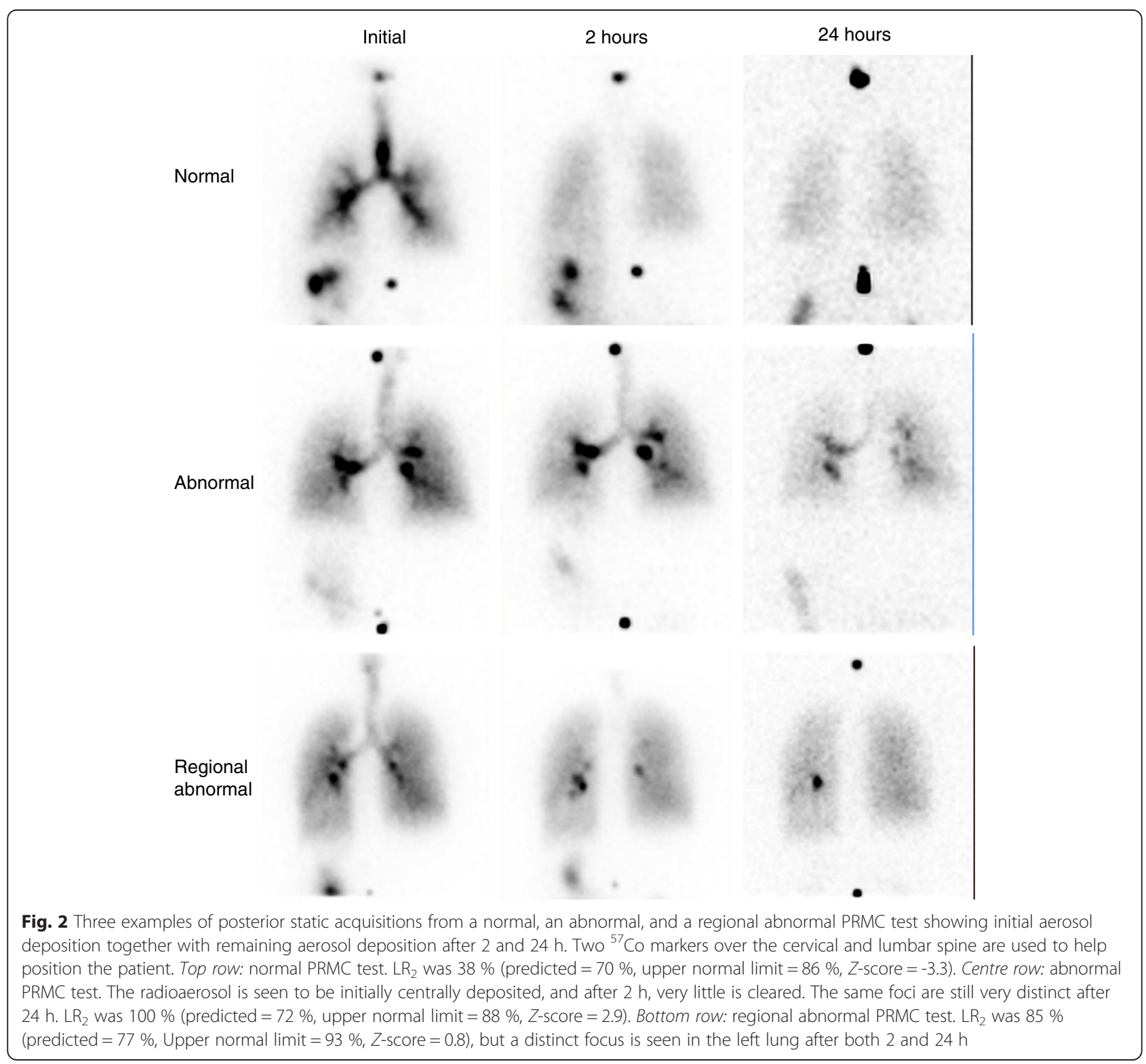


SD, respectively) to include a retention of $100 \%$. This problem is minimised by means of the inhalation technique described earlier, which serves to promote deposition of the radioaerosol in the central airways.

As noted, if the patient coughs during the first $2 \mathrm{~h}$ of the PRMC test, an apparently normal test will be interpreted as inconclusive. This is due to the fact that the clearance measured may be the result of cough clearance instead of clearance due to ciliary movement. Hence, an effective cough clearance would be able to disguise a true abnormal clearance leading the test to appear as being normal (i.e., false negative). In contrast, an abnormal test is still considered reliable despite coughing (i.e., true positive). Consequently, a staff member monitored the patients during the first $2 \mathrm{~h}$ of the test and registered time and number of coughs and throat clearing. Subsequently, all patients who had coughed in this timeframe had to perform a 1-min voluntary cough clearance test immediately after the 2-h acquisition, which served as a measure for the effectiveness of their coughing with regard to airway clearing. If this test showed minimal cough clearance, an otherwise normal PRMC test could be regarded as being normal provided that the cough during the first $2 \mathrm{~h}$ of the test had been very limited (say 1-2 small coughs or huffs). The voluntary cough clearance test is not thought to affect the interpretation of the 24-h scan, since this scan is predominantly determined by retention in the smaller bronchi, bronchioles, and possibly bronchiectasis which is only marginally affected by cough clearance, since coughing is thought mainly to affect the first six airway generations [17]. In addition, no restrictions are given to the patients with regard to coughing in the timeframe before the 24-h scan.

\section{Final clinical diagnosis}

The final clinical diagnoses were primarily obtained via national electronic hospital records, in which we were able to search for each patient by means of their unique social security number. In a few cases, this information was complemented with non-electronic records from the National PCD Centre in Copenhagen. Results from EM and ciliary function testing were found in a database in the National PCD Centre in Copenhagen where these tests are being performed. A description of these two methods can be found in the ERS recommendations for PCD [18]. All patients in Denmark with a verified, definitive PCD diagnosis are followed on a regular basis in the National PCD Centre in Copenhagen. Therefore, these patients were easy to identify.

Optimally, all patients in the study should have had their tentative PCD diagnosis confirmed or refuted after the completion of both thorough clinical assessment, nasal NO measurement, EM, ciliary function testing, PRMC, and in some cases gene testing. Because of the set-up of the study, the different tests were done only when considered pertinent by the treating doctor, meaning that only some of the patients were examined this comprehensively.

For a minority of the patients (32 out of 239), a conclusion could not be reached with regard to their final clinical diagnosis. This was most often due to lack of information in the national electronic hospital records or due to on-going work up of a patient with contradicting test results.

\section{Statistical analysis}

Two-sample $t$ test for means was used for comparisons unless both groups were larger than 30 , in which cases a $z$ test was performed instead. Comparisons were done between PI in patients with a normal and abnormal PRMC test and between PI and $Z$-scores for $\mathrm{LR}_{1}$ and $\mathrm{LR}_{2}$ for children vs. adults with a normal PRMC.

\section{Ethics}

The Danish Data Protection Agency has approved the study.

\section{Results}

\section{Overview}

In total, 239 patients with an age range of 4 to 75 years were included in this study (Table 1 ). $23.8 \%$ had a positive PRMC test (PCD/SCD), $10.5 \%$ had an inconclusive test while the remaining $65.7 \%$ had a test that ruled out PCD. The PRMC results were rather uniformly distributed with regard to age with only the group of 55- to 75-year-old patients having a lower percentage of abnormal $(7.1 \%)$ and inconclusive results $(3.6 \%)$ than the other groups (abnormal $\sim 20-35 \%$ and inconclusive $\sim 6-13 \%$ ). Consequently, they also had a higher percentage of results that were normal or otherwise not consistent with PCD.

\section{PRMC results in relation to final clinical diagnosis}

No patient with a PRMC test that ruled out PCD ended up with PCD as final clinical diagnosis (Table 2)-that is, there were no false negatives. However, $29 \%$ of patients in this group ended up with an uncertain final clinical diagnosis.

The final clinical diagnoses of patients with an abnormal PRMC test were somewhat more variable. $40 \%$ ended up with verified PCD while $39 \%$ had the PCD diagnosis rejected-that is, $39 \%$ of the positive PRMC tests were false positives. At the end of the study, $21 \%$ had an uncertain diagnosis. A similar variability in the final diagnoses was seen amongst patients with an 
Table 1 Distribution of PRMC results in relation to age

\begin{tabular}{|c|c|c|c|c|c|c|}
\hline \multirow[t]{3}{*}{ Results from PRMC test } & \multicolumn{6}{|l|}{ Age group } \\
\hline & $4-14$ years & $15-24$ years & $25-34$ years & $35-54$ years & $55-75$ years & All \\
\hline & $n=105(\%)$ & $n=28(\%)$ & $n=34(\%)$ & $n=44(\%)$ & $n=28(\%)$ & $n=239(\%)$ \\
\hline \multirow[t]{2}{*}{$\mathrm{PCD} / \mathrm{SCD}$} & $21(20)$ & $9(32.1)$ & $12(35.3)$ & $13(29.5)$ & $2(7.1)$ & $57(23.8)$ \\
\hline & {$[14,67 \%]$} & {$[3,33 \%]$} & {$[3,25 \%]$} & {$[3,23 \%]$} & {$[0]$} & {$[23,40 \%]$} \\
\hline \multirow[t]{2}{*}{ Inconclusive } & $14(13.3)$ & $3(10.7)$ & $2(5.9)$ & $5(11.4)$ & $1(3.6)$ & $25(10.5)$ \\
\hline & {$[4,29 \%]$} & {$[0]$} & {$[0]$} & {$[0]$} & {$[0]$} & {$[4,16 \%]$} \\
\hline \multirow[t]{2}{*}{ Normal or otherwise not consistent with PCD } & $70(66.7)$ & $16(57.1)$ & $20(58.8)$ & $26(59.1)$ & $25(89.3)$ & $157(65.7)$ \\
\hline & [0] & {$[0]$} & {$[0]$} & {$[0]$} & {$[0]$} & {$[0]$} \\
\hline
\end{tabular}

Numbers in square brackets show the number and percentage of patients in each group ending up with verified PCD as final clinical diagnosis

inconclusive PRMC test. PCD was rejected in $64 \%$ of cases while it was verified in $16 \%$. At the end of the study, $20 \%$ had an uncertain diagnosis.

The highest percentage of patients ending up with verified PCD as final clinical diagnosis were seen amongst children $4-14$ years old (67 \% of patients having an abnormal PRMC test) while no patients $\geq 55$ years ended up with the final clinical diagnosis of PCD (Table 1). All four patients with an inconclusive PRMC test that ended up with PCD as final clinical diagnosis were $\leq 14$ years. The reason for their PRMC tests being inconclusive was pronounced coughing resulting in $L_{1}$ and $\mathrm{LR}_{2}$ values within the normal range while bolus transport and 24-h static acquisition were abnormal.

\section{PRMC results in relation to ciliary function testing, EM, and final clinical diagnosis}

As mentioned earlier, not all patients underwent the full work up for PCD whereby it has only been possible to compare PRMC results with ciliary function testing and EM in 108 and 79 cases, respectively (Tables 3 and 4). Seventy-two patients had both tests performed. As a whole, there was good concordance between the three different test results and the final clinical diagnoses. However, in some cases, significant discrepancies were seen between results. This was mainly (1) patients with a PRMC test ruling out PCD but with an abnormal EM or ciliary function test who ended up with a final clinical diagnosis rejecting PCD, (2) patients with an inconclusive PRMC test, an abnormal EM or ciliary function test, and a final clinical diagnosis rejecting PCD, (3) patients with an abnormal PRMC test but a normal EM who ended up with a final clinical diagnosis confirming PCD, or (4) patients with an abnormal PRMC test and abnormal EM or ciliary function test but with a final clinical diagnosis rejecting PCD. All cases with discrepant results have been marked with asterisk in Tables 3 and 4, and moreover, further information about each of these patients is presented in Table 5 (please note that some of the 23 marked patients in Tables 3 and 4 are the same so that they represent only 21 different patients).

\section{Inconclusive tests}

In our study, $90 \%$ of patients had a conclusive result after just one PRMC test.

Unfortunately, only 10 out of 25 patients with an initially inconclusive PRMC test had a new PRMC test performed. However, 8 out of these 10 patients obtained a conclusive test after repeating the PRMC test once. Two patients needed more than one repetition.

\section{Comparison of penetration index and retention in different groups}

When comparing mean PI from patients with a normal and abnormal PRMC test, respectively, we found no significant difference between the two groups suggesting that a more peripheral initial deposition was not the cause of the observed abnormal clearance (mean PI for normal $\mathrm{PRMC}=0.478$, mean PI for abnormal PRMC $=0.524, \mathrm{CI}$ for difference in means $=(-0.0189 ; 0.111))$.

Table 2 PRMC results in relation to final clinical diagnosis

\begin{tabular}{|c|c|c|c|c|c|c|}
\hline \multirow{3}{*}{ Results from PRMC test } & \multicolumn{6}{|c|}{ Final clinical diagnosis } \\
\hline & Verified PCD & Uncertain but probably PCD & Uncertain & Uncertain but probably not PCD & Not PCD & Total \\
\hline & $n=27(\%)$ & $n=3(\%)$ & $n=32(\%)$ & $n=28(\%)$ & $n=149(\%)$ & $n=239(\%)$ \\
\hline $\mathrm{PCD} / \mathrm{SCD}$ & $23(85.2)$ & $2(66.6)$ & $7(21.9)$ & $3(10.7)$ & $22(14.8)$ & $57(23.8)$ \\
\hline Inconclusive & $4(14.8)$ & $1(33.3)$ & $3(9.4)$ & $1(3.6)$ & $16(10.7)$ & $25(10.5)$ \\
\hline $\begin{array}{l}\text { Normal or otherwise not } \\
\text { consistent with PCD }\end{array}$ & $0(0)$ & $0(0)$ & $22(68.7)$ & $24(85.7)$ & $111(74.5)$ & $157(65.7)$ \\
\hline
\end{tabular}


Table 3 PRMC results in relation to ciliary function testing and final clinical diagnosis

\begin{tabular}{|c|c|c|c|c|c|c|c|c|}
\hline \multirow{3}{*}{ Results from PRMC test } & \multicolumn{3}{|c|}{ Results from ciliary motility study } & \multicolumn{5}{|c|}{ Final clinical diagnosis related to results from PRMC and ciliary motility study } \\
\hline & $\begin{array}{l}\text { Abnormal, } \\
\text { consistent } \\
\text { with PCD }\end{array}$ & Inconclusive & $\begin{array}{l}\text { Normal, not } \\
\text { consistent } \\
\text { with PCD }\end{array}$ & $\begin{array}{l}\text { Verified } \\
\text { PCD }\end{array}$ & $\begin{array}{l}\text { Uncertain but } \\
\text { probably PCD }\end{array}$ & Uncertain & $\begin{array}{l}\text { Uncertain but } \\
\text { probably not PCD }\end{array}$ & Not PCD \\
\hline & $n=45(\%)$ & $n=17(\%)$ & $n=46(\%)$ & $n=25(\%)$ & $n=2(\%)$ & $n=7(\%)$ & $n=3(\%)$ & $n=71(\%)$ \\
\hline \multirow[t]{3}{*}{$\mathrm{PCD} / \mathrm{SCD}$} & $26(57.8)$ & & & $22(88)$ & $1(50)$ & - & - & $3^{\mathrm{a}}(4.2)$ \\
\hline & & $2(11.8)$ & & - & - & - & - & $2(2.8)$ \\
\hline & & & $15(32.6)$ & - & - & $3(42.8)$ & $1(33.3)$ & $11(15.5)$ \\
\hline \multirow[t]{3}{*}{ Inconclusive } & $8(17.8)$ & & & $3(12)$ & - & $1(14.3)$ & - & $4^{a}(5.6)$ \\
\hline & & $2(11.8)$ & & - & $1(50)$ & - & - & $1(1.4)$ \\
\hline & & & $8(17.4)$ & - & - & $1(14.3)$ & - & $7(9.9)$ \\
\hline \multirow{3}{*}{$\begin{array}{l}\text { Normal or otherwise not } \\
\text { consistent with PCD }\end{array}$} & $11(24.4)$ & & & - & - & $1(14.3)$ & - & $10^{\mathrm{a}}(14.1)$ \\
\hline & & $13(76.4)$ & & - & - & $1(14.3)$ & $2(66.6)$ & $10(14.1)$ \\
\hline & & & $23(50)$ & - & - & - & - & $23(32.4)$ \\
\hline
\end{tabular}

${ }^{a}$ Cases with discrepant results. Further information about each of these patients is presented in Table 5

The relation of retention $Z$-scores and PI to age was compared amongst patients who had a perfectly normal PRMC test (Fig. 3a-c). When comparing children (5-14 years) with adults ( $>14$ years), significant differences were found in the case of retention $Z$-scores for $L R_{1}$, retention $Z$-scores for $L R_{2}$, and $P I$ (Table 6).

\section{Discussion}

With its 239 patients, this is by far the largest study to date concerning clinical use of the PRMC test. Furthermore, it is the first study presenting a large data set from PRMC tests used as part of everyday clinical work up of patients suspected of having PCD.

According to our study, the main strength of the PRMC test is its ability to rule out an otherwise suspected PCD diagnosis since the study showed that no patient with a normal PRMC test or a PRMC test otherwise not consistent with PCD ended up having PCD as final clinical diagnosis - that is, we experienced no false negatives. Only $10 \%$ of tests were inconclusive, and of these, only $16 \%$ had a final clinical diagnosis of PCD. The fact that no patients $>14$ years with an inconclusive test result ended up with a definite PCD diagnosis means that even an inconclusive test in adults strongly suggests that PCD is very unlikely.

To this date, there are only few studies on the usage of PRMC in relation to PCD. Most of these studies deal only with a very limited number of patients and especially the number of PCD patients in each study is sparse [19-22]. However, these studies do show markedly reduced tracheobronchial clearance in patients with known PCD compared with healthy individuals which is in alignment with our results. Most recently, this was found by Walker et al. in a comparison of six PCD patients and four healthy controls [23]. In our earlier large

Table 4 PRMC results in relation to EM and final clinical diagnosis

\begin{tabular}{|c|c|c|c|c|c|c|c|c|}
\hline \multirow{3}{*}{$\begin{array}{l}\text { Results from PRMC } \\
\text { test }\end{array}$} & \multicolumn{3}{|c|}{ Results from EM study } & \multicolumn{5}{|c|}{ Final clinical diagnosis related to results from PRMC and EM study } \\
\hline & $\begin{array}{l}\text { Abnormal, } \\
\text { consistent } \\
\text { with PCD }\end{array}$ & Inconclusive & $\begin{array}{l}\text { Normal, not } \\
\text { consistent } \\
\text { with PCD }\end{array}$ & Verified PCD & $\begin{array}{l}\text { Uncertain but } \\
\text { probably PCD }\end{array}$ & Uncertain & $\begin{array}{l}\text { Uncertain but } \\
\text { probably } \\
\text { not PCD }\end{array}$ & Not PCD \\
\hline & $n=23(\%)$ & $n=13(\%)$ & $n=44(\%)$ & $n=26(\%)$ & $n=2(\%)$ & $n=4(\%)$ & $n=2(\%)$ & $n=46(\%)$ \\
\hline \multirow[t]{3}{*}{$\mathrm{PCD} / \mathrm{SCD}$} & $18(78.3)$ & & & $17(65.4)$ & - & - & - & $1(2.2)$ \\
\hline & & $5(38.5)$ & & $2(7.7)$ & - & $1(25)$ & - & $2(4.3)$ \\
\hline & & & $16(36.4)$ & $3^{\mathrm{a}}(11.5)$ & $1(50)$ & $1(25)$ & - & $11(23.9)$ \\
\hline \multirow[t]{3}{*}{ Inconclusive } & $3(13.0)$ & & & $2(7.7)$ & - & - & - & $1^{a}(2.2)$ \\
\hline & & $3(23.0)$ & & $1(3.8)$ & - & - & - & $2(4.3)$ \\
\hline & & & $7(15.9)$ & $1^{a}(3.8)$ & $1(50)$ & $1(25)$ & $1(50)$ & $3(6.5)$ \\
\hline \multirow{3}{*}{$\begin{array}{l}\text { Normal or otherwise } \\
\text { not consistent } \\
\text { with PCD }\end{array}$} & $2(8.7)$ & & & - & - & $1(25)$ & - & $1^{a}(2.2)$ \\
\hline & & $5(38.5)$ & & - & - & - & $1(50)$ & $4(8.7)$ \\
\hline & & & $21(47.7)$ & - & - & - & - & $21(45.7)$ \\
\hline
\end{tabular}

${ }^{a}$ Cases with discrepant results. Further information about each of these patients is presented in Table 5 
Table 5 Elaboration of patients with significant discrepancies between test results

\begin{tabular}{|c|c|c|c|c|c|}
\hline \multirow[t]{2}{*}{ Variables } & \multicolumn{5}{|l|}{ Patient } \\
\hline & 1 & 2 & 3 & 4 & 5 \\
\hline Age, years & 15 & 6 & 15 & 17 & 10 \\
\hline PRMC & PCD/SCD & $\begin{array}{l}\mathrm{PCD} / \mathrm{SCD} \text { (A normal } \\
\text { PRMC was found } \\
2 \text { years later) }\end{array}$ & $\mathrm{PCD} / \mathrm{SCD}$ & Inconclusive & Inconclusive \\
\hline $\begin{array}{l}\text { Ciliary motility } \\
\text { study }\end{array}$ & $\begin{array}{l}\text { Abnormal (but } \\
\text { some sequences } \\
\text { are described as } \\
\text { being normal) }\end{array}$ & Abnormal & $\begin{array}{l}\text { Abnormal } \\
\text { (described as only } \\
\text { slightly abnormal } \\
\text { and partly } \\
\text { inconclusive test) }\end{array}$ & $\begin{array}{l}\text { Abnormal (described } \\
\text { as being only } \\
\text { slightly abnormal) }\end{array}$ & $\begin{array}{l}\text { Abnormal (described as } \\
\text { being only slightly abnormal) }\end{array}$ \\
\hline EM & Normal & Abnormal & Normal & Normal & $\begin{array}{l}\text { Abnormal (described as } \\
\text { being only slightly abnormal) }\end{array}$ \\
\hline Nasal NO & Normal & Normal & Normal & - & Normal \\
\hline $\begin{array}{l}\text { Final clinical } \\
\text { diagnosis }\end{array}$ & Not PCD & Not PCD & Not PCD & Not PCD & Not PCD \\
\hline \multirow{3}{*}{$\begin{array}{l}\text { Comments on } \\
\text { final clinical } \\
\text { diagnosis }\end{array}$} & \multirow{3}{*}{$\begin{array}{l}\text { Recurring infections } \\
\text { apparently due to } \\
\text { immune deficiency } \\
\text { Abnormal PRMC } \\
\text { and ciliary study }\end{array}$} & $\begin{array}{l}\text { Today, } \\
\text { asymptomatic }\end{array}$ & \multirow{2}{*}{$\begin{array}{l}\text { Unknown restrictive } \\
\text { lung disease and } \\
\text { recurring upper } \\
\text { airway infections }\end{array}$} & \multirow{3}{*}{$\begin{array}{l}\text { Abnormal ciliary } \\
\text { study might be } \\
\text { due to SCD }\end{array}$} & Today, asymptomatic \\
\hline & & \multirow{2}{*}{$\begin{array}{l}\text { Abnormal PRMC, } \\
\text { ciliary study and } \\
\text { EM might be } \\
\text { due to SCD }\end{array}$} & & & \multirow[t]{2}{*}{$\begin{array}{l}\text { Abnormal ciliary study and } \\
\text { EM might be due to SCD }\end{array}$} \\
\hline & & & $\begin{array}{l}\text { Abnormal PRMC } \\
\text { and ciliary study } \\
\text { might be due } \\
\text { to SCD }\end{array}$ & & \\
\hline \multirow[t]{2}{*}{ Variables } & \multicolumn{5}{|l|}{ Patient } \\
\hline & 6 & 7 & 8 & 9 & 10 \\
\hline Age, years & 20 & 34 & 61 & 8 & 13 \\
\hline PRMC & Inconclusive & Inconclusive & Normal & Normal & Normal \\
\hline $\begin{array}{l}\text { Ciliary motility } \\
\text { study }\end{array}$ & $\begin{array}{l}\text { Abnormal } \\
\text { (described as being } \\
\text { only slightly } \\
\text { abnormal) }\end{array}$ & $\begin{array}{l}\text { Abnormal } \\
\text { (described as } \\
\text { being only } \\
\text { slightly abnormal) }\end{array}$ & $\begin{array}{l}\text { Abnormal } \\
\text { (described as } \\
\text { being only } \\
\text { slightly abnormal) }\end{array}$ & Abnormal & $\begin{array}{l}\text { Abnormal (described as being } \\
\text { only slightly abnormal) }\end{array}$ \\
\hline EM & - & Normal & - & Normal & - \\
\hline Nasal NO & - & Normal & - & Normal & - \\
\hline $\begin{array}{l}\text { Final clinical } \\
\text { diagnosis }\end{array}$ & Not PCD & Not PCD & Not PCD & Not PCD & Not PCD \\
\hline \multirow{3}{*}{$\begin{array}{l}\text { Comments on } \\
\text { final clinical } \\
\text { diagnosis }\end{array}$} & \multirow{2}{*}{$\begin{array}{l}\text { Recurring } \\
\text { aspergilloma }\end{array}$} & \multirow{3}{*}{$\begin{array}{l}\text { Abnormal ciliary } \\
\text { study might be } \\
\text { due to SCD }\end{array}$} & \multirow{2}{*}{$\begin{array}{l}\text { Asymptomatic } \\
\text { today }\end{array}$} & Asthma & Asthma \\
\hline & & & & Today asymptomatic & Today, only few symptoms \\
\hline & $\begin{array}{l}\text { Abnormal ciliary } \\
\text { study might be } \\
\text { due to SCD }\end{array}$ & & $\begin{array}{l}\text { Abnormal ciliary } \\
\text { study might be } \\
\text { due to SCD }\end{array}$ & $\begin{array}{l}\text { Abnormal ciliary } \\
\text { study might be } \\
\text { due to SCD }\end{array}$ & $\begin{array}{l}\text { Abnormal ciliary study might } \\
\text { be due to SCD }\end{array}$ \\
\hline \multirow[t]{2}{*}{ Variables } & \multicolumn{5}{|l|}{ Patient } \\
\hline & 11 & 12 & 13 & 14 & 15 \\
\hline Age, years & 10 & 11 & 7 & 8 & 13 \\
\hline PRMC & Normal & Normal & Normal & Normal & Normal \\
\hline $\begin{array}{l}\text { Ciliary motility } \\
\text { study }\end{array}$ & $\begin{array}{l}\text { Abnormal (the } \\
\text { specimen was } \\
\text { infected) }\end{array}$ & Abnormal & $\begin{array}{l}\text { Abnormal } \\
\text { (described as being } \\
\text { only slightly } \\
\text { abnormal) }\end{array}$ & Abnormal & Abnormal \\
\hline EM & Normal & Abnormal & - & Normal & Normal \\
\hline Nasal NO & Normal & Normal & Normal & Normal & Normal \\
\hline Final clinical & Not PCD & Not PCD & Not PCD & Not PCD & Not PCD \\
\hline
\end{tabular}


Table 5 Elaboration of patients with significant discrepancies between test results (Continued)

\begin{tabular}{|c|c|c|c|c|c|c|}
\hline \multirow{3}{*}{$\begin{array}{l}\text { Comments on } \\
\text { final clinical } \\
\text { diagnosis }\end{array}$} & $\begin{array}{l}\text { Severe asthma and } \\
\text { atopic dermatitis }\end{array}$ & $\begin{array}{l}\text { Today, } \\
\text { asymptomatic }\end{array}$ & $\begin{array}{l}\text { Asthma and } \\
\text { allergies }\end{array}$ & Today asymptomatic & \multicolumn{2}{|c|}{$\begin{array}{l}\text { Abnormal ciliary study might } \\
\text { be due to SCD }\end{array}$} \\
\hline & $\begin{array}{l}\text { Abnormal ciliary } \\
\text { study might be } \\
\text { due to SCD }\end{array}$ & $\begin{array}{l}\text { No explanation has } \\
\text { been found for the } \\
\text { patient's earlier } \\
\text { airway symptoms }\end{array}$ & $\begin{array}{l}\text { Today, only few } \\
\text { airway symptoms }\end{array}$ & $\begin{array}{l}\text { Abnormal ciliary } \\
\text { study might be } \\
\text { due to SCD }\end{array}$ & & \\
\hline & & $\begin{array}{l}\text { Abnormal ciliary } \\
\text { study and EM might } \\
\text { be due to SCD }\end{array}$ & $\begin{array}{l}\text { Abnormal ciliary } \\
\text { study might be } \\
\text { due to SCD }\end{array}$ & & & \\
\hline \multirow[t]{2}{*}{ Variables } & \multicolumn{6}{|l|}{ Patient } \\
\hline & 16 & 17 & 18 & 19 & 20 & 21 \\
\hline Age, years & 24 & 5 & 7 & 9 & 37 & 12 \\
\hline PRMC & Normal & Normal & $\mathrm{PCD} / \mathrm{SCD}$ & $\mathrm{PCD} / \mathrm{SCD}$ & PCD/SCD & Inconclusive \\
\hline $\begin{array}{l}\text { Ciliary motility } \\
\text { study }\end{array}$ & Abnormal & $\begin{array}{l}\text { Abnormal } \\
\text { (described as being } \\
\text { only slightly } \\
\text { abnormal) }\end{array}$ & Abnormal & Abnormal & Abnormal & Abnormal \\
\hline EM & - & Normal & $\begin{array}{l}\text { Normal (described } \\
\text { as being partly } \\
\text { inconclusive) }\end{array}$ & Normal & $\begin{array}{l}\text { Normal } \\
\text { (described as } \\
\text { being partly } \\
\text { inconclusive) }\end{array}$ & Normal \\
\hline Nasal NO & Normal & Normal & - & - & - & Abnormal \\
\hline $\begin{array}{l}\text { Final clinical } \\
\text { diagnosis }\end{array}$ & Not PCD & Not PCD & Verified PCD & Verified PCD & Verified PCD & Verified PCD \\
\hline $\begin{array}{l}\text { Comments on } \\
\text { final clinical } \\
\text { diagnosis }\end{array}$ & $\begin{array}{l}\text { Abnormal ciliary } \\
\text { study might be } \\
\text { due to SCD }\end{array}$ & $\begin{array}{l}\text { Asthma } \\
\text { Abnormal ciliary } \\
\text { study might be } \\
\text { due to SCD }\end{array}$ & $\begin{array}{l}\text { Clinically PCD is } \\
\text { plausible with } \\
\text { frequent airway } \\
\text { infections }\end{array}$ & $\begin{array}{l}\text { Clinically PCD is plausible } \\
\text { with frequent airway } \\
\text { infections and severe } \\
\text { basal bronchiectasis }\end{array}$ & $\begin{array}{l}\text { Clinically PCD is } \\
\text { plausible with } \\
\text { frequent airway } \\
\text { infections }\end{array}$ & $\begin{array}{l}\text { Clinically PCD is plausible } \\
\text { with chronic productive } \\
\text { coughing, bronchiectasis } \\
\text { and situs inversus }\end{array}$ \\
\hline
\end{tabular}

study [14], 95 patients underwent PRMC. Fifty-seven of these patients had known PCD or were diagnosed during the course of the study. The study was divided into three sequentially performed substudies: (1) a cross-sectional study of patients with known PCD which showed abnormal PRMC in 14 out of 15 patients (one PRMC was inconclusive), (2) a prospective blinded trial in which PRMC was tested against EM and ciliary function testing which showed good concordance between the different methods, and (3) an implementation study using PRMC as part of the routine work up of 21 patients referred for PCD investigation. It was concluded that in a selected group of patients, PRMC would be a good supplementary test in the diagnosis and exclusion of PCD. These observations were generally corroborated by our present results, which were obtained from a very large group of patients in which the PCD diagnosis was not established beforehand. Even though the described implementation study with 21 patients should assess PRMC as a routine method in PCD work up, one might think that the selection of patients for the trial have been affected by the fact that this new method was suddenly available to a large group of patient suspected of having PCD. One might speculate that patients with the highest suspicion of PCD would then be referred to the PRMC test first. This is in line with the fact that 6 out of 21
(29\%) had PCD as final clinical diagnosis compared with $11 \%$ in the present study. Therefore, we think that our present study better represents what to expect from the PRMC test if implemented in the everyday work up of suspected PCD patients. In addition, because of the large number of patients included in this study, for the first time, we have been able to analyse data from 42 children presenting perfectly normal PRMC tests in order to assess the reference material used today.

\section{PRMC results in relation to final clinical diagnosis}

As mentioned, one of the biggest strengths of the PRMC test is its ability to rule out PCD. This is supported by the fact that we found no false negatives in the present study.

In addition, in a selected group of patients apparently the test has the ability to point out patients that are likely to have PCD. In our study population, when the PRMC test was abnormal, $40 \%$ ended up having PCD as final clinical diagnosis. This means that an abnormal test to some degree supports the PCD diagnosis, though it is important to remember that the ability to diagnose PCD is not the main advantage of the test.

Another reason, why the PRMC test is a useful clinical tool, is its high degree of conclusive results. After just 


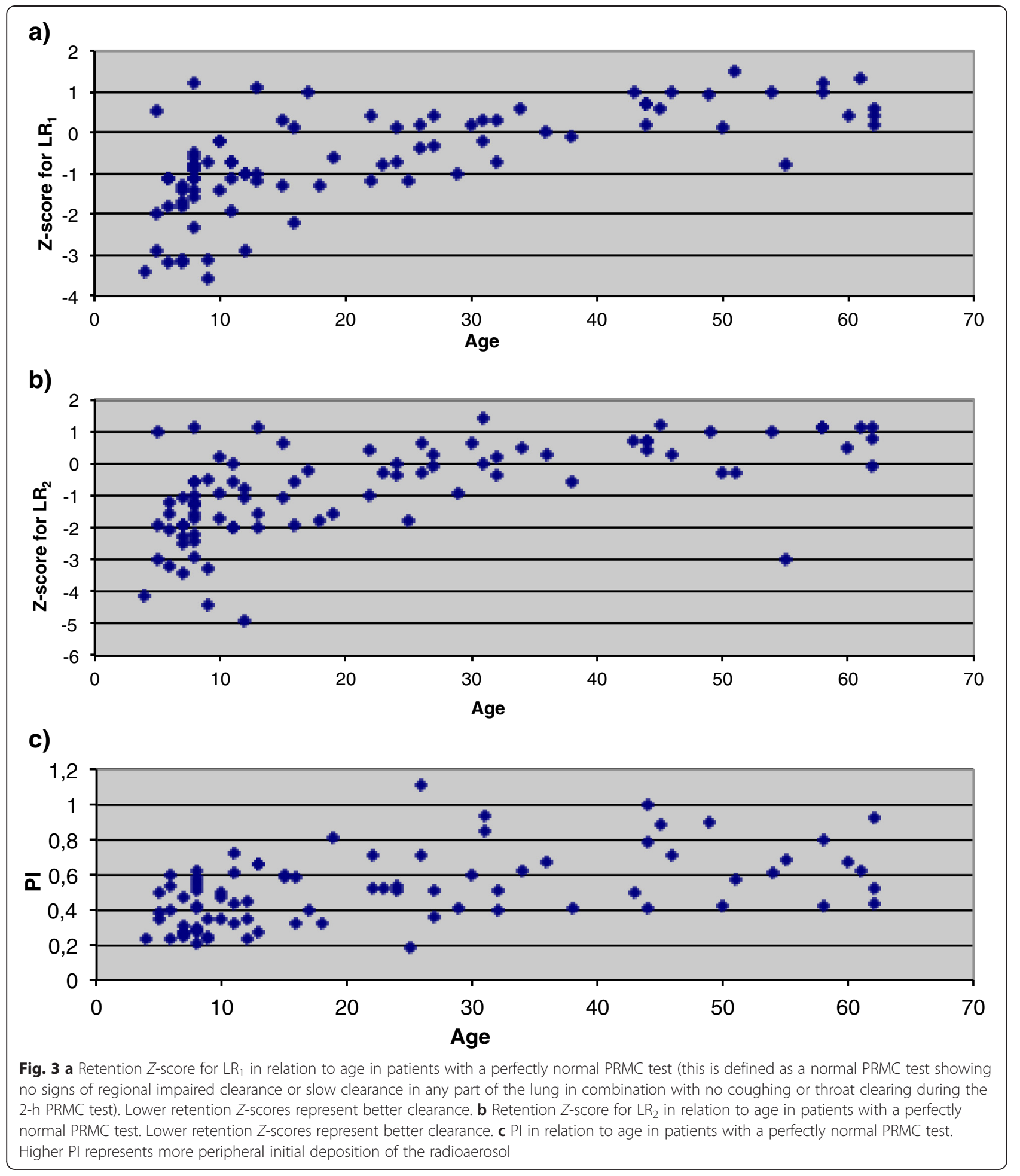

one test, $90 \%$ of patients had a conclusive result (Table 1). Eighty percent of patients initially having an inconclusive result obtained a conclusive test after only one repetition. If looking at the subgroups of patients on which either ciliary function testing or EM was performed, the rates of conclusive results after the first test were as follows: $69 \%$ of ciliary function tests were conclusive compared with $83 \%$ of PRMC tests. Seventy-five percent of EM tests were conclusive compared with $84 \%$ of PRMC tests.

As seen in Table 1, by far the largest number of patients having PCD as final clinical diagnosis was found 
Table 6 Comparison of retention Z-scores and PI between children (5-14 years) and adults (>14 years)

\begin{tabular}{lllll}
\hline & $\begin{array}{l}\text { Mean values } \\
\text { for children } \\
n=42\end{array}$ & $\begin{array}{l}\text { Mean values } \\
\text { for adults } \\
n=44\end{array}$ & $\begin{array}{l}\text { Difference of the } \\
\text { means }(95 \% \mathrm{Cl})\end{array}$ & $p$ value \\
\hline Z-score for $\mathrm{LR}_{1}$ & -1.4 & 0.089 & $1.47(1.05 ; 1.89)$ & $p<0.001$ \\
$Z$-score for $\mathrm{LR}_{2}$ & -1.7 & -0.0023 & $1.65(1.15 ; 2.15)$ & $p<0.001$ \\
PI & 0.40 & 0.61 & $0.2(0.127 ; 0.276)$ & $p<0.001$ \\
\hline
\end{tabular}

All the included patients had a perfectly normal PRMC test. (This is defined as a normal PRMC test showing no signs of regional impaired clearance or slow clearance in any part of the lung in combination with no coughing or throat clearing during the 2-h PRMC test)

in the group of patients being 4-14 years old and having an abnormal PRMC test while none over the age of 55 was diagnosed with PCD. This is in line with the clinical presentation of the disease starting in early childhood and most often resulting in severe airway symptoms often leading to early work up.

Generally, the results from ciliary function testing and EM were in good concordance with results from the PRMC tests and the final clinical diagnoses. However, some discrepancies were seen. Each of these cases has been elaborated further, and they are all presented in Table 5. In 17 out of the 21 cases (patient No. 1-17), the observed discrepancy is thought to be due to SCD causing false positive tests. In 10 out of these 17 cases (patient No. 8-17), the patient had a PRMC test not consistent with PCD while the ciliary function testing was abnormal. The fact that SCD could affect the results of ciliary function testing and not PRMC could be explained in two ways: First, the different tests are not necessarily performed at the same point in time, which means that the degree of SCD affecting the patient might differ between the two tests. Second, and more importantly, one of the great advantages of the PRMC test is that it is not affected by nasal SCD because the PRMC test examines the ciliary function of the entire lung and not just the nasal ciliary function.

In four other cases (patient No. 18-21), a normal EM was found while the rest of the tests were abnormal together with a final clinical diagnosis confirming PCD. This is in line with a growing number of publications showing normal EM tests in PCD patients [2, 9, 24, 25, 26].

\section{Penetration index and Z-scores}

We found no significant difference between the initial aerosol distribution in the lungs (indicated by the mean PI) in patients with a normal and abnormal PRMC test. The magnitude of PI is accounted for when calculating predicted values for $\mathrm{LR}_{1}$ and $\mathrm{LR}_{2}$. But if PI had been significantly higher in patients with an abnormal PRMC test, this would have implied that we did not to a satisfactory degree take into account the magnitude of PI when calculating predicted values. Fortunately this does not seem to be the case, which means that abnormal test results are most likely caused solely by slow clearance of the radioaerosol.

When comparing children and adults presenting perfectly normal PRMC tests, our results show markedly faster clearance (i.e., lower $Z$-scores for $L_{1}$ and $L R_{2}$ ) in children than in adults. This might be an expression of the fact that children under 14 years of age have smaller lungs and thereby generally shorter airways than adults [27]. Assuming that the cilia in healthy children and adults work equally effective, it makes sense that shorter airways means faster overall lung clearance.

It is also noteworthy that the mean PI in these children is significantly lower (i.e., more central initial lung deposition) than the mean PI seen in the corresponding adults. According to the discussion above, this should not affect the results of the test seeing that the magnitude of PI is accounted for in the calculation of predicted $L R_{1}$ and $L R_{2}$. Nevertheless, it raises the question if the formulas for calculating predicted $L R_{1}$ and $L R_{2}$ to a satisfactory degree take the magnitude of PI into account when used on children under 14 years of age. If not, at least to some degree, the low PI seen amongst the children might explain the faster clearance observed. If the fast clearance observed in children is primarily due to smaller lungs, it would make sense to incorporate, e.g., the height of the patient when calculating PI. As of today, PI only takes into account the proportion of the lung receiving a certain degree of radioaerosol. Thereby, the actual size of the lungs and thus the length of the airways are not accounted for.

Whatever the explanation, according to our results, it seems fair to state that the reference material used for the PRMC test today does not in a satisfactory degree take into account the effect of age (or height) on lung clearance, which is most evident for children under 14 years of age. This is not surprising since our reference material is based upon a cross-sectional study of 53 healthy never-smoking adults (18 to 84 years) meaning that predictive norms have been extrapolated for ages $<18$. In the reference material, the dependency of age on PRMC was weak [16]. But according to the present study, this could be different if one incorporates children $<14$ years in such a reference material. To date, no reference material on PRMC in children exists.

\section{Algorithm for work up of PCD in specialised centres with access to PRMC testing}

Based on our experience with work up of patients suspected of having PCD, we propose the following algorithm for PCD investigation (Fig. 4).

When patients have been referred to a specialist centre with expertise in PCD work up, the ensuing work up should take into account the strength of suspicion of PCD based on history and clinical presentation of the 


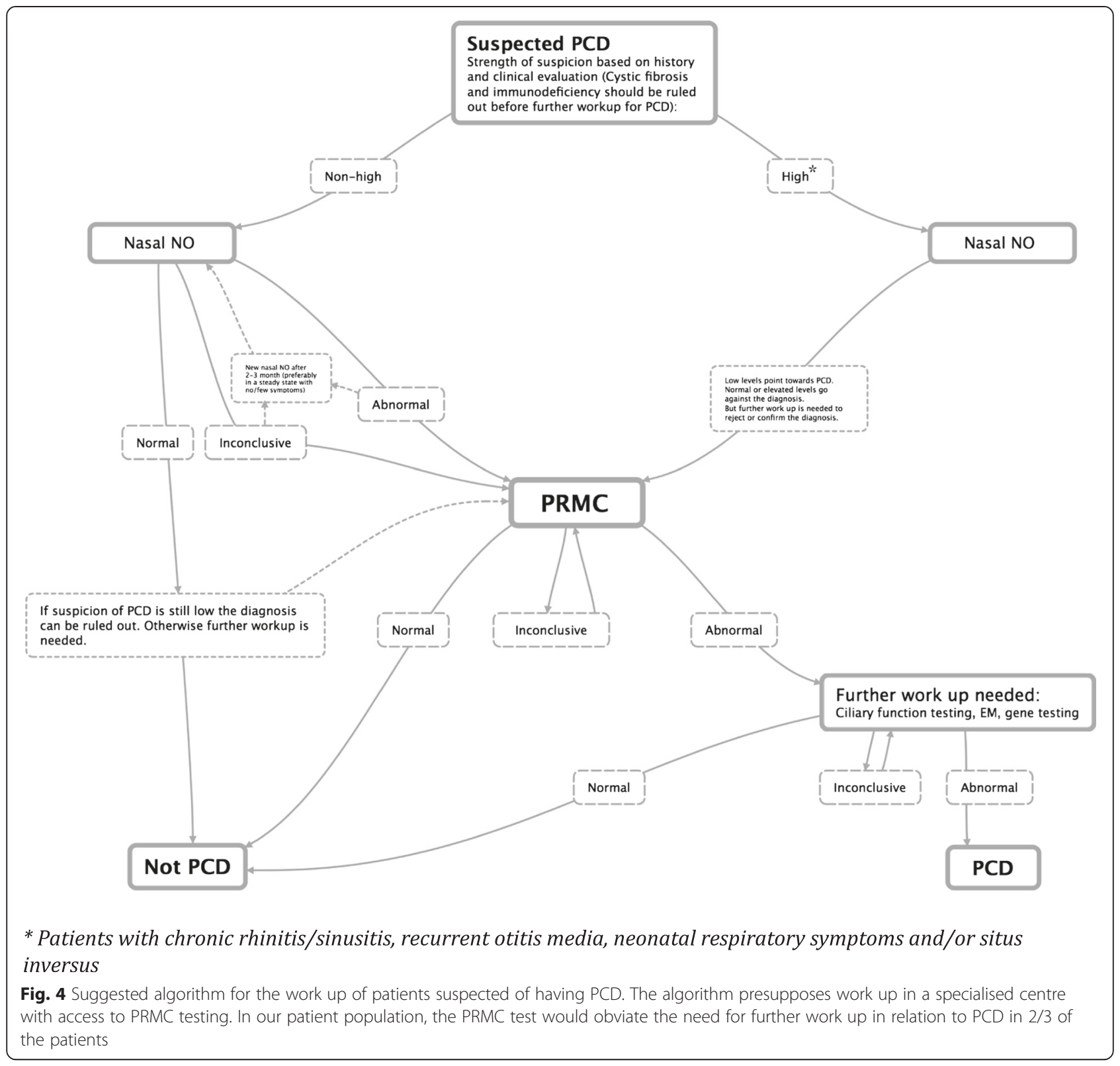

patient [28]. However, whether the initial suspicion is high or non-high, measurement of nasal NO levels should be used as a first wave work up tool. The test is easy to perform and non-invasive and is suitable as a targeted case finding tool for PCD [2]. In patients with a normal or high level of nasal NO together with a nonhigh suspicion of PCD, the diagnosis could be ruled out. If however the suspicion is high, further work up for PCD should be performed since a few studies have shown normal or elevated levels of nasal NO in patients with known PCD [11, 13, 29]. A low level of nasal NO points towards PCD, but other conditions such as cystic fibrosis [30], panbronchiolitis [31], nasal polyposis [32], and chronic sinusitis [32] have also been shown to demonstrate reduced levels of nasal NO. Therefore, a measurement of low nasal NO should always be followed by further work up to confirm or reject the diagnosis. This work up should amongst other things include a new nasal NO measurement after, e.g., 23 months-preferably in a steady state with no or few symptoms apart from those to be expected from the disease. If rising or normal values can then be attained, the diagnosis might be rejected [33, 34].

Patients with initially high suspicion of PCD and all patients with abnormal or inconclusive nasal $\mathrm{NO}$ values should have PRMC performed. If the PRMC test is normal, PCD can be ruled out in accordance with the fact that we found no false negatives in the present study. In 
our setting, PCD could be ruled out in roughly two out of three patients. An inconclusive test would require a re-test (in the present study $80 \%$ acquired a conclusive result after only one re-test) while an abnormal test should lead to more intensive work up with EM, ciliary function testing, and possibly gene testing.

\section{Strengths and weaknesses of the study}

One of the main strengths of the present study is that it shows what to expect of the PRMC test if implemented in the everyday clinical work up of PCD. Another strength is the large number of patients that are included. By far, it is the largest study to date concerning clinical use of the PRMC test. Furthermore, even when taking into account the weaknesses mentioned in the following, the fact that no patient with a normal PRMC test ended up with PCD as final clinical diagnosis is quite convincing. It is also worth noticing the very high rate of conclusive results achieved with the PRMC test.

The main weakness of this study is that all of the PRMC results have been used in the subsequent work up of the patients, which means that these results have inevitably affected the final clinical diagnoses. In addition, not all patients underwent the same thorough work up for PCD. This was due to the fact that in some patients, the assumed PCD diagnosis was easily rejected leaving some tests unnecessary in the everyday clinical work up for PCD. It would of cause be advantageous to make a similar study with blinded results and with strict protocols for the work up of all patients suspected of having PCD. On a smaller scale, this was done by Marthin et al. [14] in our substudy 2, which included 59 patients, and as mentioned, those results are generally in line with the results presented in the present work. Another weakness of the present study is the lack of systematically collected clinical information concerning smoking habits, airway symptoms, and pulmonary diseases that might influence mucociliary clearance. On the other hand, we know that all patients in general had unexplained airway symptoms (or else they would not have been referred to the PRMC test) and that they as far as possible had been without acute airway infection 4-6 weeks prior to the test as already explained.

\section{Conclusions}

In this study, we have evaluated the use of the PRMC test in the work up of patients suspected of having PCD. To this date, it is the only method for testing the mucociliary function of the lower airways, and when compared to other existing tests, one of its great strengths is that it is not affected by secondary mucociliary defects affecting nasal cilia. In addition, the test is non-invasive and is applicable to children as young as 5 years of age. The method is relatively easy to introduce and perform and could therefore potentially be of interest for general nuclear medicine departments if used for research purposes such as to investigate possible links between mucociliary dysfunction and pathophysiology of lung diseases or pharmacological challenges to the mucociliary apparatus [1]. But if used in the work up of patients suspected of having PCD, the interpretation of tests needs expertise in addition to a relatively large population of patients (in concordance with the infrequent nature of the disease). However, it is yet to be established if these tests/results can be replicated in less-experienced nuclear medicine facilities after a proper amount of training.

From the above, we can conclude the following: (1) in the present study, we found no false negatives. We therefore believe that PRMC has the ability to reject a suspected PCD diagnosis with great certainty, when used in daily clinical work up (in the present study in $2 / 3$ of referred patients). (2) PRMC has the ability to find candidates for further work up. In the present study, $40 \%$ of patients with an abnormal PRMC test ended up having PCD as final clinical diagnosis. This number will of course depend greatly upon the group of patients being investigated. (3) PRMC has a high rate of conclusive results ( $90 \%$ in the present study). (4) In addition, our results indicate that there might be a need for reference material for children.

\section{Competing interests}

The authors declare that they have no competing interests.

\section{Authors' contributions}

MM participated in conceiving the study, performed the statistical analyses, and drafted the manuscript. KGN provided and interpreted the information obtained from the National PCD Centre in Copenhagen and participated in the construction of the algorithm (Fig. 4) in cooperation with the other

authors. JM conceived the study, participated in its coordination, and helped to draft the manuscript. All authors read and approved the final manuscript.

\section{Acknowledgements}

We thank the bioanalytical technologist in the Department of Clinical Physiology, Nuclear Medicine \& PET, Rigshospitalet, for their help in performing the mucociliary clearance studies. In addition, we thank biologist Maria Philipsen from the National PCD Centre in Copenhagen for her help with retrieving and analysing EM and ciliary motility data.

\section{Author details}

${ }^{1}$ Department of Clinical Physiology, Nuclear Medicine \& PET, Rigshospitalet, Copenhagen University Hospital, DK-2100 Copenhagen $\varnothing$, Denmark. ²Danish PCD Centre, Pediatric Pulmonary Service, Department of Pediatrics and Adolescent Medicine, Rigshospitalet, Copenhagen University Hospital, Copenhagen, Denmark. ${ }^{3}$ Department of Medicine, Nuclear Medicine section, The Faroese National Hospital, Torshavn, Faroe Islands.

Received: 9 April 2015 Accepted: 6 July 2015

Published online: 16 July 2015

\section{References}

1. Munkholm M, Mortensen J. Mucociliary clearance: pathophysiological aspects. Clin Physiol Funct Imaging. 2014;34(3):171-7.

2. Barbato A, Frischer T, Kuehni CE, Snijders D, Azevedo I, Baktai G, et al. Primary ciliary dyskinesia: a consensus statement on diagnostic and treatment approaches in children. Eur Respir J. 2009;34(6):1264-76. 
3. Hellinckx J, Demedts M, De Boeck K. Primary ciliary dyskinesia: evolution of pulmonary function. Eur J Pediatr. 1998;157(5):422-6.

4. Ellerman A, Bisgaard H. Longitudinal study of lung function in a cohort of primary ciliary dyskinesia. Eur Respir J. 1997;10(10):2376-9.

5. Bush A, Chodhari R, Collins N, Copeland F, Hall P, Harcourt J, et al. Primary ciliary dyskinesia: current state of the art. Arch Dis Child. 2007;92(12):1136-40.

6. Leigh MW, O'Callaghan C, Knowles MR. The challenges of diagnosing primary ciliary dyskinesia. Proc Am Thorac Soc. 2011;8(5):434-7.

7. Lucas JS, Burgess A, Mitchison HM, Moya E, Williamson M, Hogg C. Diagnosis and management of primary ciliary dyskinesia. Arch Dis Child. 2014;99(9):850-6.

8. Omran H, Loges NT. Immunofluorescence staining of ciliated respiratory epithelial cells. Methods Cell Biol. 2009;91:123-33.

9. Olbrich H, Schmidts M, Werner C, Onoufriadis A, Loges NT, Raidt J, et al. Recessive HYDIN mutations cause primary ciliary dyskinesia without randomization of left-right body asymmetry. Am J Hum Genet. 2012;91(4):672-84

10. Hirst RA, Rutman A, Williams G, O'Callaghan C. Ciliated air-liquid cultures as an aid to diagnostic testing of primary ciliary dyskinesia. Chest. 2010;138(6):1441-7.

11. Marthin JK, Nielsen KG. Choice of nasal nitric oxide technique as first-line test for primary ciliary dyskinesia. Eur Respir J. 2011;37(3):559-65.

12. Rutland J, de longh RU. Random ciliary orientation. A cause of respiratory tract disease. N Engl J Med. 1990;323(24):1681-4.

13. Marthin JK. Nasal nitric oxide and pulmonary radioaerosol mucociliary clearance as supplementary tools in diagnosis of primary ciliary dyskinesia. Dan Med Bull. 2010;57(8):B4174

14. Marthin JK, Mortensen J, Pressler T, Nielsen KG. Pulmonary radioaerosol mucociliary clearance in diagnosis of primary ciliary dyskinesia. Chest. 2007;132(3):966-76.

15. Mortensen J, Jensen C, Groth S, Lange P. The effect of forced expirations on mucociliary clearance in patients with chronic bronchitis and in healthy subjects. Clin Physiol. 1991;11(5):439-50.

16. Mortensen J, Lange P, Nyboe J, Groth S. Lung mucociliary clearance. Eur J Nucl Med. 1994;21(9):953-61.

17. Yeates DB, Mortensen J. Deposition and clearance. In: Murray JFNJ, editor. Textbook of respiratory medicine. 3rd ed. Philadelphia: WB Saunders Company; 2000. p. 349-84

18. Afzelius BA. Cilia-related diseases. J Pathol. 2004;204(4):470-7.

19. Camner P, Mossberg B, Afzelius BA. Measurements of tracheobronchial clearance in patients with immotile-cilia syndrome and its value in differential diagnosis. Eur J Respir Dis Suppl. 1983;127:57-63.

20. Pavia D, Sutton PP, Agnew JE, Lopez-Vidriero MT, Newman SP, Clarke SW. Measurement of bronchial mucociliary clearance. Eur J Respir Dis Suppl. 1983;127:41-56

21. Zwas ST, Katz I, Belfer B, Baum GL, Aharonson E. Scintigraphic monitoring of mucociliary tracheo-bronchial clearance of technetium-99m macroaggregated albumin aerosol. J Nucl Med. 1987;28(2):161-7.

22. Mortensen J. Bronchoscintigraphy and pulmonary clearance of $99 \mathrm{mTc}$-albumin colloid in the study of mucociliary clearance. Dan Med Bull. 1998;45(2):195-209.

23. Walker WT, Young A, Bennett M, Guy M, Carroll M, Fleming J, et al. Pulmonary radioaerosol mucociliary clearance in primary ciliary dyskinesia. Eur Respir J. 2014;44(2):533-5

24. Schwabe GC, Hoffmann K, Loges NT, Birker D, Rossier C, de Santi MM, et al. Primary ciliary dyskinesia associated with normal axoneme ultrastructure is caused by DNAH11 mutations. Hum Mutat. 2008;29(2):289-98.

25. Pifferi M, Cangiotti AM, Ragazzo V, Baldini G, Cinti S, Boner AL. Primary ciliary dyskinesia: diagnosis in children with inconclusive ultrastructura evaluation. Pediatr Allerg Immunol. 2001;12(5):274-82.

26. Escudier E, Duquesnoy P, Papon JF, Amselem S. Ciliary defects and genetics of primary ciliary dyskinesia. Paediatr Respir Rev. 2009;10(2):51-4

27. Chiang CC, Jeffres MN, Miller A, Hatcher DC. Three-dimensional airway evaluation in 387 subjects from one university orthodontic clinic using cone beam computed tomography. Angle Orthodontist. 2012;82(6):985-92.

28. Noone PG, Leigh MW, Sannuti A, Minnix SL, Carson JL, Hazucha M et al. Primary ciliary dyskinesia: diagnostic and phenotypic features. Am J Respir Crit Care Med. 2004;169(4):459-67.
29. Pifferi M, Bush A, Caramella D, Di Cicco M, Zangani M, Chinellato I, et al. Agenesis of paranasal sinuses and nasal nitric oxide in primary ciliary dyskinesia. Eur Respir J. 2011;37(3):566-71.

30. Balfour-Lynn IM, Laverty A, Dinwiddie R. Reduced upper airway nitric oxide in cystic fibrosis. Arch Dis Child. 1996;75(4):319-22.

31. Nakano H, Ide H, Imada M, Osanai S, Takahashi T, Kikuchi K, et al. Reduced nasal nitric oxide in diffuse panbronchiolitis. Am J Respir Crit Care Med. 2000;162(6):2218-20.

32. Colantonio D, Brouillette L, Parikh A, Scadding GK. Paradoxical low nasal nitric oxide in nasal polyposis. Clin Exp Allerg. 2002;32(5):698-701.

33. Piacentini GL, Bodini A, Peroni D, Rigotti E, Pigozzi R, Pradal U, et al. Nasal nitric oxide for early diagnosis of primary ciliary dyskinesia: practical issues in children. Respir Med. 2008:102(4):541-7.

34. Piacentini GL, Bodini A, Peroni DG, Sandri M, Brunelli M, Pigozzi R, et al. Nasal nitric oxide levels in healthy pre-school children. Pediatr Allerg Immunol. 2010;21(8):1139-45.

\section{Submit your manuscript to a SpringerOpen ${ }^{\circ}$ journal and benefit from:}

- Convenient online submission

- Rigorous peer review

- Immediate publication on acceptance

- Open access: articles freely available online

- High visibility within the field

- Retaining the copyright to your article

Submit your next manuscript at $>$ springeropen.com 